\title{
Las personificaciones de dioses y seres sobrenaturales de Yaxchilán
}

\author{
Macarena S. LóPEZ OLIvA \\ Doctorado en Historia y Arqueología \\ Universidad Complutense de Madrid \\ macarenl@estumail.ucm.es
}

Recibido: 25 de septiembre de 2015

Aceptado: 19 de julio de 2016

\section{RESUMEN}

Este artículo analiza las personificaciones de seres sobrenaturales por parte de personajes de la elite política de Yaxchilán, Chiapas, México, que hicieron su aparición durante el periodo Clásico Tardío maya y que se manifestaron sucesivamente durante los gobiernos de «Dios D» B'ahlam II, Yaxuun B'ahlam IV y Chelew Chan $\mathrm{K}$ 'inich, a través de estos gobernantes y de algunos nobles y mujeres importantes de sus gobiernos.

Palabras clave: Personificaciones, seres sobrenaturales, conjuros, «Dios D» B'ahlam II, Yaxuun B'ahlam IV, Chelew Chan K'inich.

\section{The Impersonations of Gods and Supernatural Beings in Yaxchilan}

\begin{abstract}
This article analyses impersonations of supernatural beings by characters of the political elite in Yaxchilan, Chiapas, Mexico, which occurred during the Late Classic Maya period and continued to be exhibited by rulers and other noble men and women during the successive governments of «God D» B'ahlam II, Yaxuun B'ahlam IV and Chelew Chan K'inich.
\end{abstract}

Key words: Impersonations, supernatural beings, spells, «God D» B'ahlam II, Yaxuun B'ahlam IV, Chelew Chan K'inich.

Sumario: 1. Introducción. 2. Contextos de personificaciones en el reinado de «Dios D» B'ahlam II. 3. Contextos de personificaciones en el reinado de Yaxuun B'ahlam IV. 4. Contextos de personificaciones en el reinado de Chelew Chan K'inich. 5. Conclusiones. 6. Referencias bibliográficas.

\section{Introducción}

Este trabajo se centra en las manifestaciones divinas y sobrenaturales que se canalizaron a través de los gobernantes y personas importantes de la nobleza, en Yaxchilán (México), reino conocido en el Clásico maya como Pa'chan.

Las relaciones entre deidades, reyes y altos nobles han sido previamente estudiadas por algunos autores (Houston y Stuart 1996; Nehammer et al. 2009; Velásquez 2010). Houston y Stuart identificaron una frase distintiva, que introduce los nombres de reyes y nobles importantes y que generalmente acompaña los retratos de éstos, cuando se los representa como personificadores. La frase en cuestión se componía de la palabra «bah» (sic) más el sufijo posesivo -il y un logograma. En conjunto leyeron la frase como «u-bah-il ANUM» ${ }^{1}$, y la tradujeron como «(esta es) la imagen de...

\footnotetext{
1 Cito textualmente la forma en que transcriben y transliteran Houston y Stuart (1996); no obstante, debo aclarar que sigo las reglas ortográficas propuestas por Alfonso Lacadena y Søren Wichmann (2004, 2005; ver también Lacadena 2010).
} 

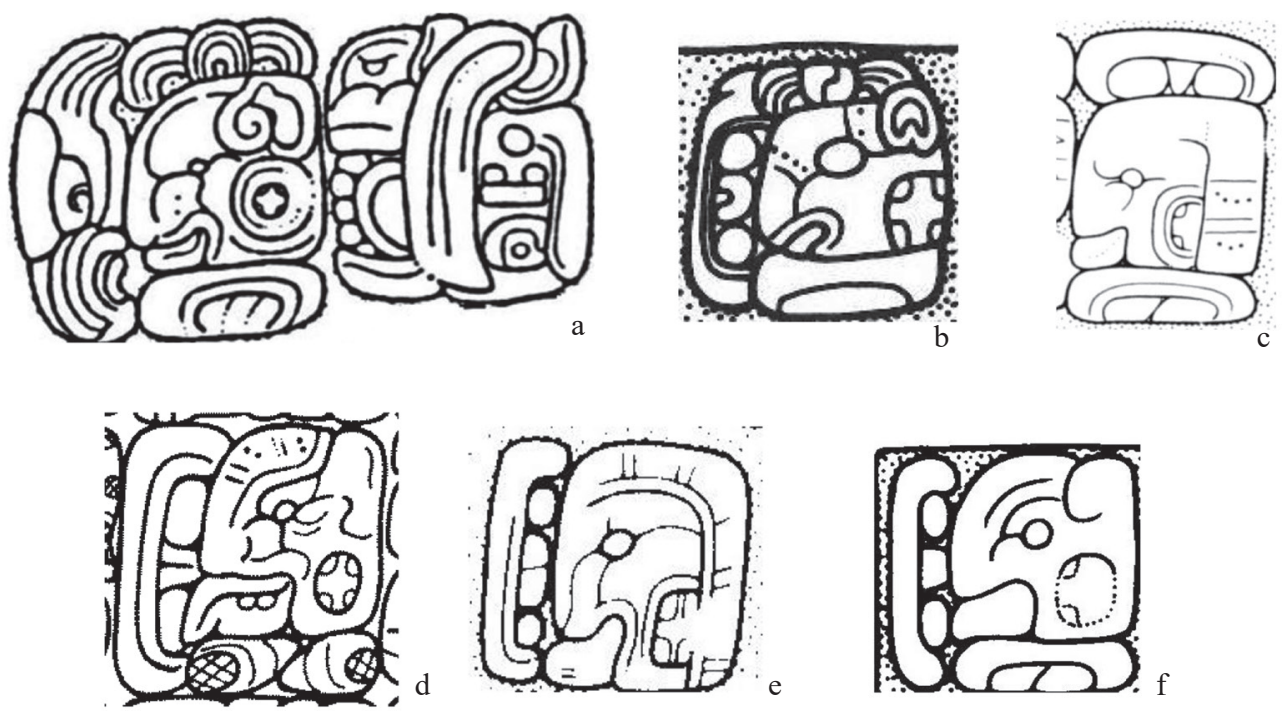

Figura 1: Variantes epigráficas de la frase $u b^{\prime}$ 'aahil a'n en Yaxchilán y otros sitios; a) Puerta de Jamba 3, Pomoná: u-B'AH-hi-li a-AN $u b^{\prime}$ 'aahil a 'n; b) Dintel 14, Yaxchilán: u-B'AH-hi-li AN $u b$ 'aahil a 'n; c) Escalera Jeroglífica 3, Escalón 4, Yaxchilán: u-B'AH-li-AN ub'aah[i]l a'n; d) Estela 18, Yaxchilán: u-B'AH AN-nu $u b^{\prime} a a h[i l] a^{\prime} n$; e) Estela 13, Naranjo: u-B'AH AN $u b^{\prime} a a h[i l]$ a'n; f) Dintel 15, Yaxchilán: u-B'AH-li «AN» ub'aah[i]l a'n.

el famoso 'dios'» (Houston y Stuart 1996: 299; 1998: 76, nota 4), traduciendo anum como «famoso» (1996: 299). Actualmente, la frase se conoce como ub'aahil a'n (Figura 1) y va seguida del nombre de un ser sobrenatural y luego de un antropónimo. «Al portar el adverbio de existencia $a$ 'n, las construcciones $b$ 'aahil a' $n$ podrían operar en estos pasajes como oraciones o sentencias completas que equiparan a una persona con alguna cosa o característica: '[él] es la personificación'» (Velásquez 2010: 203). Sin embargo, la traducción de b'aahil a'n como «personificación» es sólo semánticamente aproximada, ya que no se ha encontrado así en ningún diccionario de lenguas mayas. Por esta razón Erik Velásquez la traduce como «es la presencia corporal de» (2010: 206-207). No obstante, en este trabajo utilizaré la traducción semántica, o sea: «es la personificación de».

Con esta frase se ha comprendido que para los mayas del Clásico existió una estrecha relación entre los seres sobrenaturales y la realeza (y eventualmente la nobleza), abriendo con esto un nuevo campo para el estudio del mundo sobrenatural y religioso de los mayas del Clásico. Se ha planteado que los reyes y altos nobles personificaban, o más bien, eran la manifestación de algunos dioses; poseían habilidades especiales para asumir la identidad de ciertos seres sobrenaturales, a través de rituales de personificación. Por esta razón, bajo especiales circunstancias, la distinción entre gobernantes y deidades es vaga (Houston y Stuart 1996: 297).

2 Todas las traducciones al español de textos originalmente en inglés y alemán son de la autora. 
La identificación de los gobernantes con dioses y seres sobrenaturales nos indica lo importante que era el mundo religioso para los antiguos mayas, ya que, por lo visto, no existía una separación tajante entre el mundo sobrenatural y el mundo «natural»o, como diría López Austin (2006), entre el anecúmeno y el ecúmeno ${ }^{3}$. Esto sugiere que, efectivamente, los dioses y seres sobrenaturales interactuaban en el mundo de los seres vivos, el cual, de alguna manera, debía desarrollarse en función de esos seres. Esta idea se empieza a vislumbrar con el estudio de las personificaciones, las que no sólo funcionaron quizás, como una estrategia de legitimación del gobernante ante sus súbditos, sino que también pudieron funcionar como una forma efectiva de contacto con los dioses y los seres sobrenaturales dominantes de las distintas ciudades mayas.

Para acercarnos a la comprensión del fenómeno de las personificaciones, a continuación se analizan las que se registraron en Yaxchilán. Las personificaciones de seres sobrenaturales en esa ciudad comienzan con el gobernante «Dios D» ${ }^{4} \mathrm{~B}$ 'ahlam II, en el año 677 d.C. La costumbre de representar miembros de la elite personificando seres sobrenaturales continuó por dos generaciones más, o sea, con el hijo y el nieto de «Dios D» B'ahlam II, los gobernantes Yaxuun B'ahlam IV y Chelew Chan $\mathrm{K}^{\prime}$ inich ${ }^{5}$, respectivamente. El último monumento que nos muestra personificaciones está fechado en el 755 o 768 d.C. y corresponde al gobierno de Yaxuun B'ahlam IV. El gobernante que representó más personificaciones de seres sobrenaturales en los monumentos fue Yaxuun B'ahlam IV, lo que no extraña considerando todos los problemas que tuvo que sortear para acceder al trono y legitimarse (Martin y Grube 2002: 128; Mathews 1997: 195, 221, 360; Schele y Freidel 1990: 263-264, 272-273, 285, 291). Su hijo, Chelew Chan K'inich, no aparece personificando a ningún ser sobrenatural, ya que el monumento realizado durante su gobierno, y que señala personificaciones, es retroactivo y trata de su madre y tío materno.

\section{Contextos de personificaciones en el reinado de «Dios D» B'ahlam II}

La primera vez que aparece la frase $u b^{\prime}$ 'aahil a'n en las inscripciones de Yaxchilán es en la Estela 18, fechada en el año 677, o sea, cuatro años antes de que «Dios D» B'ahlam II ascendiera al poder ${ }^{6}$. Por esta razón, es posible que el gobernante la hu-

\footnotetext{
3 Alfredo López Austin utiliza el término ecúmeno en el sentido de ámbito del cosmos ocupado por las criaturas, pero también poblado por los entes sobrenaturales. Lo opone al término anecúmeno como la parte reservada a los seres sobrenaturales (López Austin 2006: 95).

4 La lectura del glifo «Dios D» aún no está descifrada, se lo conoce en la literatura como Itzam o Kokaaj pero ninguna de estas lecturas es segura (Marc Zender com. pers., diciembre 2015), por eso lo nombraré como «Dios D».

5 El nombre de este gobernante ha sido controvertido, ya que no ha habido consenso en cómo se debería escribir. Se lo ha nombrado anteriormente como Chelte’ Chan K'inich, Itzam o Kokaaj («Dios D») B'ahlam III y Chelet Chan K'inich. Marc Zender (com. pers., diciembre 2015) propone la lectura del nombre como Chelew, ya que el signo que se había identificado como el logograma TE', él lo lee como el silabograma we, y es esta lectura la que utilizaré.

6 La fecha registrada en la Estela 18 es problemática (3 Eb'14 Molo 'w) ya que 14 Molo'w no es equiparable con $3 \mathrm{~Eb}$ '. La única fecha que coincide con el gobierno de Kokaaj B'ahlam II es 3 Eb' 15 Molo 'w 9.14.17.15.12 (15 julio 729) G6; sin embargo, Peter Mathews señala que la fecha registrada «es claramente una referencia a (9.12.5.2.11) 2 Chuen $14 \mathrm{Mol}$, consignado en el Escalón I de la Escalera Jeroglífica 3, fecha
} 
biese encargado para rememorar un evento del pasado de gran importancia, que pudo legitimar su ascenso al poder.

En esta estela se señala la captura de Aj Popol Chay Aj Payal Mo'l, un señor de Xukal Naah: chuhkaj Aj Popol Chay Aj Payal Mo'l Xukal Naah ajaw. El texto continua con la oscura frase: ub'aak ch'ahb'ti [...] ak'b'aal ch'aho'm [...] Chan [...] K'in Tahn [...la'y] ub'aahil a'n K'ahk' "Chan» Chan K'awiil [...]. «[El señor Aj Popol Chay Aj Payal Mo'l] es el cautivo por génesis y oscuridad, del varón [...] Chan [...] K'in Tahn [...la'y] (apelativo de «Dios D» B'ahlam II), (quien) es la personificación de K'awiil-«〈Serpiente» de Fuego del Cielo [...]».

La inscripción podría indicar que la captura de Aj Popol Chay Aj Payal Mo'l ocurrió debido a algún ritual de penitencia que realizó «Dios D» B'ahlam II, en el que personificó a K’awiil-«Serpiente» de Fuego del Cielo, quizás en alusión a la serpiente que lleva K'awiil en su pierna, la que se ha identificado, en otras inscripciones, como $w a h y^{7}$. De hecho, algunos autores sugieren que la serpiente que aparece en las invocaciones o conjuros de Yaxchilán es la propia pierna de K'awiil. Esta pierna serpentina se ha denominado de varias maneras y se ha definido como el wahy de K'awiil, o de la persona que realiza el conjuro (Valencia y García 2010: 249).

No obstante, no queda claro si lo que está personificando «Dios D» B' ahlam II es el wahy de K'awiil o una advocación de éste. Tampoco el texto señala a K'awiil como un dios, quizás porque no lo sea, al menos en Yaxchilán, o porque se asume que se está hablando de uno de los atributos del dios.

El único indicio que nos da la estela para identificar la personificación de «Dios D» B'ahlam II es la cabeza de serpiente que lleva en su tocado, rodeada de largas plumas. El gobernante aparece vestido de manera marcial y a sus pies se encuentra su cautivo, el señor Aj Popol Chay Aj Payal Mo'l. Se puede inferir que la personificación de «Dios D» B'ahlam II se relacionaría con un atributo guerrero o bélico del ser sobrenatural que encarna: K’awiil-«Serpiente» de Fuego del Cielo.

Cuatro años después del evento de la Estela 18, se señala otra personificación en el Dintel 25, fechado el 23 octubre de $681^{8}$, el día de la ascensión al poder de «Dios D» B'ahlam II. Este dintel se relaciona claramente con su entronización (Mathews 1997: 137, 139; Prager 2013: cuadro 53, 369) y quizás lo realizó para justificar su ascenso al trono, en el contexto de varias estrategias, entre las que se pueden contar la representación de una serie de ceremonias dedicadas a celebrar este importante evento que se expone en los dinteles dedicados a su esposa, la Señora K'ab'al Xook (Valencia y García 2010: 242).

En este dintel se señala un conjuro sagrado realizado por «Dios D» B' ahlam II al k'awiilaal, el pedernal, el escudo de Aj K'ahk' O' Chahk. A pesar de que no se comprende bien qué es el k'awiilaal (quizás una imagen de K'awiil), se entiende que la

en la que se capturó a Chuen de Lacanhá. Este mismo suceso está registrado en la Estela 18» (1997: 163). La fecha 9.12.5.2.11 equivale al 26 de julio de 677 y es anterior a la fecha de gobierno de Kokaaj B'ahlam II. Mathews también propone la fecha 9.12.5.2.12 ? (Mathews 1997: 5) que caería 3 Eb' 15 Molo'w, y se correlaciona con el 27 de julio de 677, o sea, sólo un día después de la fecha que propone para la estela.

7 Los wahy son seres sobrenaturales del Clásico maya asociados al nagualismo, las prácticas mágicas, el chamanismo y la brujería (Stuart 2005; Velásquez 2009; Asensio 2015; López Oliva 2013: 68).

8 Todas las fechas que se consignan corresponden al calendario gregoriano. En el calendario juliano esta fecha corresponde al 20 de octubre de 681 . 
invocación se realiza a través de la figura de éste, «y que el personaje surgido de esa invocación es Ajk'ahk'O'Chaahk con su 'pedernal y su escudo'» (Valencia y García 2010: 242). Este personaje representa a un guerrero con escudo, lanza, «turbante» e «insignias teotihuacanas», y una máscara de «rayos X» que incluye anteojeras de Tlaloc (Velásquez 2007: 19-20). De esta forma, Aj K'ahk' O' Chahk se relaciona con Tlaloc -el personaje que surge de las otras fauces de la serpiente bicéfala-, no sólo por llevar una máscara de «rayos $\mathrm{X}$ » de aquel, sino porque ambos comparten los mismos atributos en sus tocados, destacando el signo del año mexicano, que los mayas «asociaron con el complejo de sacrificio Tlaloc-Venus y con imaginería conectada con Puh o Tollan ${ }^{9}$ (Schele y Mathews 1998: 413). Por otra parte, Tlaloc es un símbolo de guerra y de sangramiento que utilizaron muchas sociedades mesoamericanas, incluyendo Teotihuacan. Este complejo simbólico no sólo señaló guerra y conquista, sino que también identificó lugares y linajes con el concepto de Tollan. Posteriormente, se identificó con el dios de la lluvia (Schele y Mathews 1998: 416) del Centro de México.

En este contexto ritual encontramos la personificación que aparece en este dintel - ub'aahil a'n ixik O'hl "Witenaah» ${ }^{10} C h$ 'aho'm ixik K'ab'al Xook-, donde se señala que Ixik K'ab'al Xook (la principal esposa de «Dios D» B'ahlam II), es la personificación de la Señora O'hl «Witenaah»Ch'aho'm, un ser sobrenatural o ancestro mítico quizás, muy poco conocido.

Es posible que la personificación que encarna la Señora K'ab'al Xook se relacione con el cráneo con orejera de $k$ 'an, que ella sostiene en su antebrazo y del cual aflora una pequeña serpiente, ya que en su cabeza se observa otra pequeña serpiente, bicéfala, en una de cuyas cabezas lleva también una orejera de $k$ 'an. De hecho, la cabeza superior de la serpiente se asemeja más al cráneo que la señora sostiene en su antebrazo, que al cráneo de una serpiente propiamente tal. En cambio, la cabeza inferior de la serpiente representa la cabeza esqueletizada de ésta, o quizás el cráneo de un chapaht o ciempiés.

$\mathrm{Al}$ parecer, los mayas y nahuas prehispánicos, creían en la existencia de una entidad anímica ${ }^{11}$ que se concentraba en la cabeza (jol o jo $l$ ), funcionando ésta como su

\footnotetext{
9 Stuart descifró el nombre de Teotihuacan, en lengua maya, como $P u$ o $P u h$ «junco, totora», y lo traduce como «el lugar de los juncos, (equivalente al nombre nahuatl Tollan)». De hecho, plantea que la Tollan mítica se refiere a Teotihuacan (Stuart 2000: 466, 502, 504). Puh posiblemente fue el nombre maya para Teotihuacan y otras ciudades que se representaron como lugares de origen. Los habitantes del «lugar de los juncos» eran los Aj Puh. Tollan o Tulan fue el nombre del Centro de México para el lugar de origen donde nacieron los dioses patrones. Consistía en una montaña de serpiente rodeada de un pantano lleno de juncos. Cerca había un juego de pelota en un lugar cráneo, Itzompan, del cual emergían aguas dulces de la tierra. Los primeros habitantes de Tollan, los «toltecas», fueron grandes artistas, poetas, constructores, y guerreros (Schele y Mathews 1998: $415,417)$.

10 Tokovinine sugiere que la transcripción es Wiin Te' Naah, y que corresponde a un topónimo de algún lugar en el oeste, quizás en Teotihuacan, asociado con la mayor revuelta política en el Sureste de las Tierras Bajas mayas durante el periodo Clásico Temprano (Fash et al. 2009; Martin 2003; Stuart 2000, 2004, en Tokovinine 2014 Ms). También señala que el significado previsto de wiin te' podría ser «madera que aparece en la distancia», la que pudo verse en una gran fogata en una pirámide. El autor indica que hay varios ejemplos del título de «señor de Wiin Te' Naah» en las inscripciones del Clásico maya y parece que podría estar declarado por gobernantes extranjeros, pero también por señores mayas que viajaron a, y derivaron alguna legitimidad desde Wiin Te' Naah (Tokovinine 2014 Ms).

11 La entidad anímica o energía anímica que se supone reside en los centros anímicos se concibe frecuentemente como una unidad estructurada con capacidad de independencia, en algunas condiciones, del sitio
} 
centro anímico ${ }^{12}$. Vestigios de esta antigua concepción se pueden encontrar entre algunos grupos mayas contemporáneos. El nombre de esa entidad anímica era b'aahis, «cabeza, frente, rostro, cuerpo, ser, imagen» o «retrato», palabra que se refiere a la región cefálica como el área que facilita el reconocimiento individual y donde se ubican la mayoría de los sentidos -oído, gusto, vista y olfato-(Velásquez 2009; Houston y Scherer 2010: 175).

En la zona maya existió la costumbre de apropiarse y conservar los cráneos o cabezas de ciertas personas (ver Landa 1959: 59,60), ya fuera para el culto a los ancestros, o probablemente para capturar la entidad anímica del enemigo que residía en ellas. Esto debió hacerse para el beneficio de la comunidad y/o del guerrero -y su familia directa- que capturaba la cabeza de un enemigo. Probablemente, la apropiación de la cabeza o cráneo de un ancestro, para su culto y veneración, lo haya convertido con el tiempo en un ser sobrenatural muy poderoso, dependiendo de la efectividad que haya tenido el culto de ese ancestro, llegando incluso a poder deificarse posteriormente (López Oliva 2013: 50).

Es posible que el cráneo que sostiene la Señora K'ab'al Xook haya sido del ancestro que ella estaba personificando, o sea, de la Señora O'hl «Witenaah»Ch'aho'm, y la serpiente que emana de ese cráneo, sea la representación de la entidad anímica que se alojaba en la cabeza de los seres humanos, el b'aahis, según la concepción maya, la que podría ser la energía encargada y necesaria para que se manifieste la personificación del ancestro en cuestión.

La personificación efectiva del ancestro, quizás se representó aquí a través de la pequeña serpiente bicéfala que se encuentra junto a la cabeza de la señora $\mathrm{K}$ 'ab'al Xook, la que probablemente es el b'aahis o una parte de éste, del ser representado con el cráneo, que está personificando la Señora K'ab'al Xook.

Alfredo López Austin interpretó, en el Códice Laud $^{13}$, la representación de las distintas entidades anímicas que conforman al ser humano y que se disgregan al momento de la muerte. Éstas se representan con «cuatro figuras serpentiformes, dos de ellas con cabezas de ofidio, una con cabeza del dios del viento, Ehécatl, y la restante rematada con un cráneo» (López Austin 2008: 361); y señaló que el tonalli-el equivalente nahua del b'aahis-, estaba representado por la serpiente que asciende de la coronilla de aquella representación (Figura 2).

Pese a la diferencia temporal, en el Dintel 25 y la Estela 35 de Yaxchilán encontramos representada la misma idea que identificó López Austin (2008: 361) con la salida del tonalli en el Códice Laud, ya que en ambos monumentos se observa una serpiente que asciende de la coronilla de los cráneos que sostienen las Señoras K'ab'al Xook (Figura 3a) (López Oliva 2013: 260) y Uh Chan ${ }^{14}$ (Figura 3b).

\footnotetext{
orgánico en el que se le ubica (López Austin 2008: 197).

12 De acuerdo con López Austin, para los nahuas del Centro de México, en el cuerpo humano existían tres grandes centros anímicos mayores, entendiendo por centro anímico a «la parte del organismo humano en la que se supone existe una concentración de fuerzas anímicas, de sustancias vitales, y en la que se generan los impulsos básicos de dirección de los procesos que dan vida y movimiento al organismo y permiten la realización de las funciones psíquicas» (López Austin 2008: 197).

13 Manuscrito del Centro de México que forma parte del Grupo Borgia, y está fechado en el Posclásico Tardío, entre los siglos XIII y XV (Noguez 2006).

14 Más adelante se habla del Dintel 35 y de la Señora Uh Chan o Ik’ Joloom, como se la conocía antes.
} 
Figura 2: Códice Laud (44); serpiente identificada por López Austin (2008: 361) con la entidad anímica tonalli.
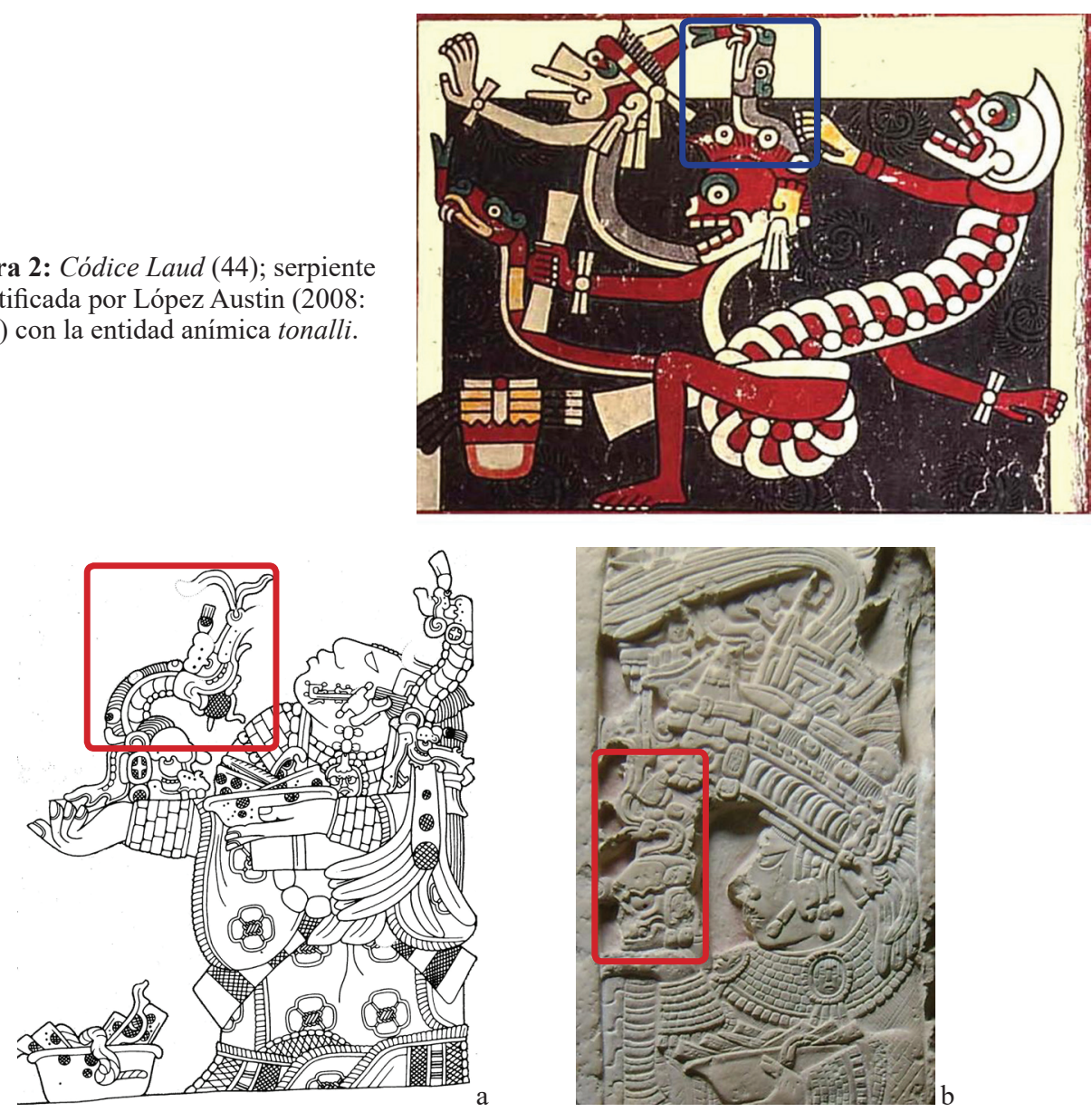

Figura 3: Representación de la salida del tonalli en dos monumentos de Yaxchilán (nótese la misma representación que aparece en la Figura 2, Códice Laud); a) detalle del Dintel 25: la señora K'ab'al Xook sostiene en su antebrazo derecho un cráneo de cuya coronilla asciende una serpiente (dibujo de Ian Graham 1977); b) detalle de la Estela 35, frente (fotografía de la autora): la señora Uh Chan sostiene un cráneo de cuya coronilla brota lo que parece ser una serpiente.

Finalmente, 42 años después de la personificación registrada en el Dintel 25, encontramos la última personificación consignada en el Gobierno de «Dios D» B'ahlam II, en el Escalón 4 de la Escalera Jeroglífica 3. En este escalón se señala que «entró el fuego» -frase dedicatoria relacionada con ceremonias rituales de renovación, que se hicieron en algunas construcciones (Stuart 1998)- en la casa de «Dios D» B'ahlam II, quien es la personificación de [...] «Dios del Maíz» (del) Sur «Yok’in», un ser sobrenatural poco conocido hasta el momento. Hay que señalar que los glifos presentes en B2a no han sido descifrados, pero al parecer la variante de cabeza representada podría ser la del llamado «Dios del maíz». No obstante, la inscripción no señala la palabra $k$ 'uh «dios», por lo tanto, es posible que la personificación que encarna «Dios 
D» B'ahlam II no se relacione con un dios, sino con un ser sobrenatural de otra categoría vinculado al maíz. Lamentablemente, este escalón carece de iconografía que nos pueda ayudar a identificar al ser sobrenatural mencionado.

\section{Contextos de personificaciones en el reinado de Yaxuun B'ahlam IV}

Durante el gobierno de Yaxuun B'ahlam IV se representaron al menos tres personificaciones, indicadas en tiempos anteriores a su época de gobierno: Estela 35, Dintel 39 y la Escalera Jeroglífica 2, Escalón 7. En la Estela 35 y el Dintel 39, ambos fechados el 1 de julio de 741, aparecen dos personificaciones diferentes.

La Estela 35 (Figura 4a) representa a su madre realizando un ritual similar al que hizo la Señora K'ab'al Xook en el Dintel 25, estableciendo así un claro paralelo con las ceremonias ejecutadas por la esposa principal de su padre. Este monumento fue realizado por Yaxuun B'ahlam IV durante su gobierno, probablemente con la intención de legitimarse en el poder, a través de un simbolismo ritual similar al que realizó su padre. Con estas ceremonias intentaba situar a su madre en el mismo nivel que la Señora K'ab'al Xook, ya que su madre era «una reina de rango menor» proveniente de Calakmul (Martin y Grube 2002: 128, 129).

El texto principal señala: tzahkaj K'awiil ukab'jiiy Chan K'inich Chan «G3» ub'aajil a'n ti ch'ab'ti ak'b'aal ixik Uh Chan T121 ixik aj k'uhu'n, «fue conjurado $\mathrm{K}$ 'awiil por Chan K' inich Chan 'G3' quien es personificado - en génesis y oscuridadpor la sacerdotisa, la señora Uh Chan». No queda claro si Chan K'inich y Chan «G3» corresponden a un mismo personaje o son dos seres distintos. No obstante, es posible que se esté aludiendo a un solo personaje, considerando que al parecer en estos ritos se personificaba a un ser y no a dos o más simultáneamente.

Observando el paralelo que existe con el Dintel 25, el ser sobrenatural que está personificando la Señora Uh Chan podría corresponder también a algún ancestro, ya que la mujer se encuentra sosteniendo un cráneo del que aflora la cabeza de una serpiente o ciempiés. El cráneo que sostiene -con orejera de $k$ 'an-aparece también en la parte frontal de su tocado -con rasgos teotihuacanos-, como en una especie de desdoblamiento donde se está enfatizando, quizás, la personificación materializada.

La influencia teotihuacana o del Centro de México la encontramos en el tocado de la mujer, que tiene dos elementos característicos: el primero, se observa en el cráneo, que lleva un tocado con un signo similar al glifo del año mexicano, en una especie de pedernal atado. El segundo elemento, que porta la Señora Uh Chan en su tocado es claramente el signo del año mexicano, que como vimos, se asociaba con el complejo de sacrificio Tlaloc-Venus y con imaginería conectada con Teotihuacan o Tollan (Schele y Mathews 1998: 413).

Junto a la mujer, se encuentra la serpiente de K'awiil que fue conjurada, de cuyas fauces sale la cabeza de Tlaloc, símbolo que refuerza la idea de que estamos ante un personaje de procedencia teotihuacana ${ }^{15}$. En conjunto, los elementos que lleva la

15 La única ciudad importante geopolíticamente - contemporánea en esta época-, y procedente del Centro de México, era Teotihuacan, por lo que asumo que la influencia viene de ese sitio. 
Figura 4: Estela 35. En ambas caras aparece representada la señora Uh Chan, la madre de Yaxuun B'ahlam IV; a) cara frontal: la señora Uh Chan personifica a Chan K'inich Chan «G3», el ser que está conjurando a K'awiil; b) cara posterior: la misma señora realiza un ritual de penitencia, de autosacrificio por sangramiento de la lengua. Dibujo de Peter Mathews.

Señora Uh Chan nos indican que el ser que está personificando se relacionaría con algún linaje de Teotihuacan o Tollan, siendo esta última de origen mítico.

Por otra parte, los Tlaloc que aparecen en la escena (se observa un segundo Tlaloc cubierto con las plumas del tocado de la mujer) podrían simbolizar el sangramiento que ella está consumando. De hecho, esta invocación fue realizada por la Señora Uh Chan durante algún ritual de penitencia (similar al que hizo «Dios D» B'ahlam II en la Estela 18), bajo su condición de ixik ajk'uhu'n o «sacerdotisa». Esta penitencia ritual se representa en la cara posterior de la Estela 35, donde aparece la mujer sangrándose la lengua con una cuerda que la traspasa (Figura 4b). Este ritual de sangra-
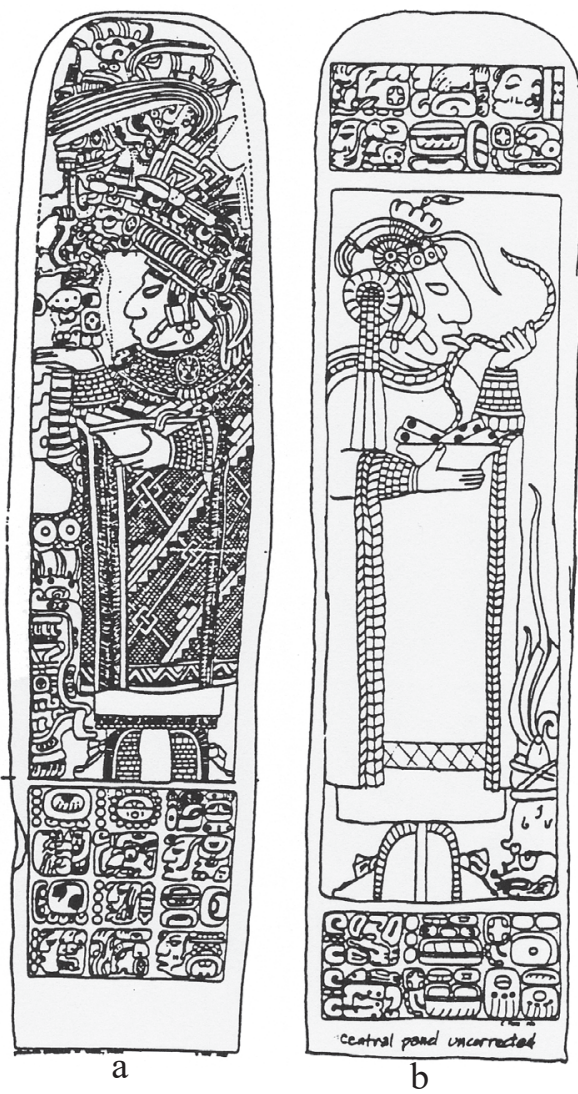
miento se pudo ejecutar para conjurar a K'awiil o para realizar la personificación, y tendrá que explicarse en futuras investigaciones.

Por último, la oscura frase que señala «génesis y oscuridad» es un difrasismo asociado con el ritual de penitencia que involucra el autosacrificio por sangramiento de la lengua u otras partes del cuerpo (Knowlton 2010).

El Dintel 39, fechado -al igual que la Estela 35- el 1 de julio de 741, nos señala en su texto: tzakk'awiil ukab'jiiy [...] jatz'no'm ub'aahil a'n «Te'el» Kuy Xukub' «vasija invertida» ${ }^{16}$ Chan [... $]$ Yaxuun B'ahlam, «fue la conjuración de K'awiil por el que golpea, Yaxuun B'ahlam, quien es la personificación de «Te'el» Kuy Xukub' «vasija invertida» ${ }^{17}$ Chan $[\ldots]$ » (Figura 5 ). Este es el único texto donde se señala

16 El glifo «vasija invertida» corresponde al signo T1001 del catálogo de Eric Thompson (1962).

17 Nikolai Grube (2012) propuso la lectura Sip para los glifos T291 «cuerno de venado» y «vasija invertida con cruz infija». Éste último, lo diferencia explícitamente del logograma T1001 «vasija invertida con signo $k^{\prime}$ 'in infijo», señalando que corresponde a un signo distinto que se asocia al título femenino que aparece particularmente en la zona del Usumacinta. Sin embargo, en este dintel (39, glifo C1), aparece el logograma «vasija invertida con signo $k^{\prime}$ 'in infijo» reemplazando a la «vasija invertida con cruz infija», que Grube identificó con Sip, lo que indica que probablemente ambos signos están relacionados. De esta forma, la vasija invertida asociada a las mujeres debería leerse Sip también, pero el fonograma -la -que tiene de sufijo-, que aquél logograma lleva a veces como complemento fonético (y que aparece, precisamente, en este ejemplo), descarta la 


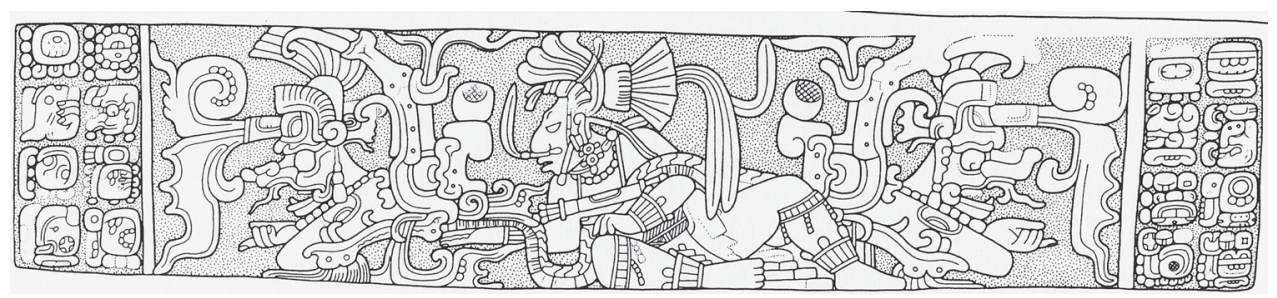

Figura 5: Dintel 39. Conjuro a K'awiil y personificación de Yaxuun B'ahlam IV de «Te’el» Kuy Xukub' («vasija invertida») Chan [...]. Dibujo de Ian Graham (1979).

explícitamente que Yaxuun B'ahlam IV está personificando a un ser -cuyo nombre no está descifrado completamente-, conocido como «Te'el» Kuy Xukub' «vasija invertida» Chan $[\ldots]$.

La iconografía del Dintel 39 no muestra elementos distintivos que ayuden a identificar el ser que personifica Yaxuun B'ahlam IV. Sin embargo, parte del nombre de ese ser puede traducirse como «Lechuza del Bosque» o «Lechuza Silvestre» (Alfonso Lacadena com. pers. 2014), lo que nos puede dar pistas para futuras identificaciones iconográficas. El eje de la escena es la serpiente bicéfala de K'awiil -que aquel sujeta con una mano y con parte de su cuerpo-, de cuyas fauces va saliendo K'awiil, explicitando con esto el conjuro a este ser que indica el texto. Sin embargo, este ritual al parecer es muy importante, ya que es lo que permitió al gobernante personificar al ser que posteriormente llevará como parte de su apelativo en varias inscripciones.

Los contextos epigráficos donde Yaxuun B'ahlam IV lleva el apelativo "Te'el» Kuy Xukub' «vasija invertida» Chan [...], sin que se señale en la inscripción que lo está personificando, son: las Estelas 1, 11 y 12, los Dinteles 1, 5, 21 y 33, y el Dintel 2 de La Pasadita. Todas las fechas registradas en estos monumentos son posteriores (747 -siendo ésta anterior a su ascensión al poder-, 752, 761 y 766 d.C., respectivamente) a la registrada en el Dintel 39 (1 de julio 741) donde se conjura a K'awiil y se personifica a «Te'el» Kuy Xukub' «vasija invertida» Chan [...].

Esto nos indica que quizás ese ritual selló de alguna forma una especie de alianza entre ese ser y Yaxuun B'ahlam IV, para que aquel pudiera ser personificado por el gobernante de allí en adelante. Quizás por esa razón, a partir de ese momento nunca más se registra en los textos a Yaxuun B'ahlam IV personificándolo, sino que se registra el nombre del ser sobrenatural como apelativo del gobernante, como si implícitamente se entendiera que lo está personificando, o al menos, llevando parte de sus atributos consigo.

lectura de Sip. Por otra parte, ese logograma a veces lleva el sufijo -ba como complemento fonético (por ej. en la Estela 10 de Yaxchilán), lo que ha dificultado aún más su desciframiento. Finalmente, hay que señalar, que la «vasija invertida con cruz infija» también aparece a veces con el sufijo -la como complemento fonético, por ejemplo, en el costado de la Estela 11 (en contexto de la cuenta de 819 días) y en la Estela 12 de Yaxchilán. Por esta razón, consideraré que la lectura del glifo T291 «cuerno de venado»-que muchas veces aparece asociado a la vasija invertida con cruz infija, y que Grube incorpora como parte del glifo «Sip»- corresponde a Xukub', según fue descifrado por Lopes y Davletshin (2004), y que la lectura de ambos signos con vasija invertida (con cruz o signo $k$ 'in infijos) permanece indescifrada. 


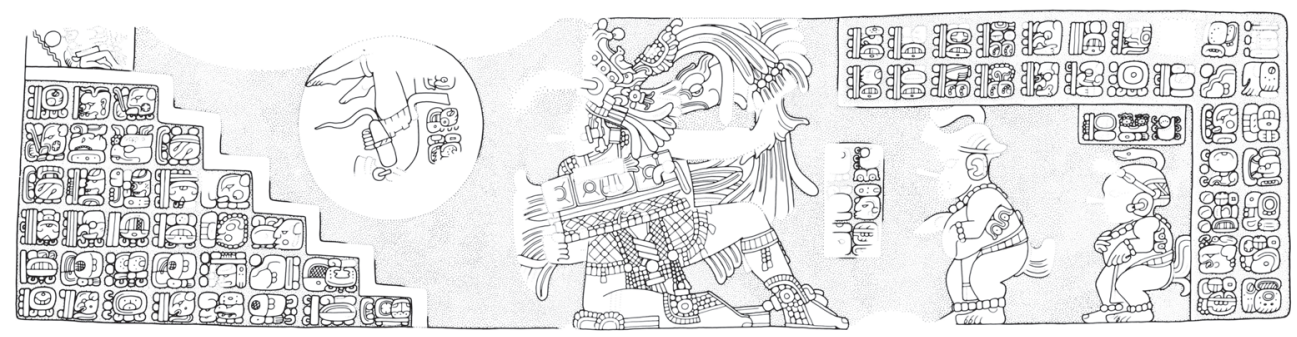

Figura 6: Escalera Jeroglífica 2, Escalón 7. Dibujo de Ian Graham (1982).

Este ritual parece ser tan importante que pudo haber sido un requisito necesario de legitimación al poder en términos religiosos, como una especie de prueba iniciática, ya que en varios eventos posteriores, e incluso cuando llegó al poder (estelas 11 y 12), ya llevaba consigo el apelativo que obtuvo luego de personificar a «Te'el» Kuy Xukub' «vasija invertida» Chan [...], un ser sobrenatural del que conocemos muy poco.

Los monumentos anteriormente señalados generalmente indican -en lo que quizás sea una acepción completa del nombre de ese ser-, su relación con el Mixnal o Inframundo, lo que nos orienta bastante sobre su campo de acción. De hecho, sólo en cuatro monumentos (Estela 12 y Dinteles 5, 21 y 39) no encontramos mencionada su relación con el Mixnal, estando presente en todos los demás.

Lo que se menciona en los otros monumentos asociado al apelativo de «Te'el» Kuy Xukub' «vasija invertida» Chan [...] Mixnal, que ostenta Yaxuun B'ahlam IV, son: 1) la cuenta de 819 días (Estelas 1 y 11) -en las Estelas 11 y 12, también se menciona su ascenso al poder, joyaj ti ajawlel «su debut en el señorío»-; 2) ceremonias de baile (Dinteles 1, 5 y 33), y 3) un ritual de arrojar/esparcir (uchoko'w), lo que parece ser la propia sangre de Yaxuun B'ahlam IV (Dintel 2, La Pasadita).

La Escalera Jeroglífica 2, Escalón 7, es otro monumento que narra eventos ocurridos antes de la entronización de Yaxuun B'ahlam IV (Figura 6). El evento registrado está fechado el 21 de octubre de 744, y señala: jatz'naj ux ahaal "juego de pelota» yehb'aal/yehb 'al? ub'aahil a'n Yax Chiit Jun Witz'Naah Kan Yaxuun B'ahlam, «fue golpeado el juego de pelota de los tres despertares/creaciones ${ }^{18}$, la escalera de Yaxuun B'ahlam, quien es la personificación de Yax Chiit Jun Witz' Naah Kan».

El texto está asociado iconográficamente con la representación del juego de pelota, y previamente, nos narra tres decapitaciones de seres sobrenaturales acaecidas en un tiempo mítico, de las cuales surgen tres despertares o creaciones, posiblemente en alusión a la creación de un nuevo orden o de un nuevo mundo.

Yaxuun B'ahlam IV aparece vestido como jugador de pelota y de unas escaleras rueda un cautivo representado dentro de una pelota. De acuerdo a Stuart, con el sa-

18 Algunos autores traducen la palabra ahaal como «conquista» (Schele y Grube 1990; Zender 2004), no obstante, Stuart (2003: 27) la transcribió como ahil y la tradujo como «'despertar' o, de manera más figurativa, 'creación'. Si bien la transcripción actual es ahaal, concuerdo con la traducción de Stuart, y es en ese sentido como la utilizo, ya que ahal en maya yucateco (incluido el lacandón) significa «despertar» (Arzápalo 1995-I, III: 6, 1140; Barrera Vásquez 1980: 3, 123; Boot 1997: 4), al igual que aji y ajal en mopán (ALMG 2003: 14; Ulrich y Ulrich 1976: 21). 
crificio de este prisionero -y probablemente de muchos más- Yaxuun Bahlam IV participa directamente del evento de «creación» (Stuart 2003), ya que en este acto sacrificial realizado en un momento histórico, el rey hace eco de las decapitaciones de los tres seres sobrenaturales que ocurrieron en los profundos tiempos mitológicos (Freidel et al. 1993, en Zender 2004: 8; Martin y Grube 2002: 130).

Este pasaje relata temas míticos, ya que el texto nos remonta a la fecha 13.13.13. 13.13.13.13.13.9.15.13.6.9, 3 Muluk, $[17 \mathrm{Mak}]^{19}$. Los últimos cinco dígitos de esta misteriosa fecha corresponden a la tradicional Cuenta Larga (9.15.13.6.9, 3 Muluk, $17 \mathrm{Mak}$ ), que se correlaciona con el 21 de octubre de 744 d.C., día donde se señala que «fue golpeado el juego de pelota de los tres despertares/creaciones, la escalera de Yaxuun Bahlam». La inscripción que nos narra sobre las tres decapitaciones, se remonta a la enrevesada fecha anterior, la que utilizó Yaxuun B'ahlam IV perspicazmente para recrear el evento mítico de las tres creaciones, conmemorándolo con su propio evento de «golpear el juego de pelota de los tres despertares o creaciones», a través del sacrificio del cautivo que rueda por las escaleras del juego. El vínculo directo entre ambos sucesos no sólo se da en el tema común de los «tres despertares o creaciones» y los sacrificios ocurridos en ellas; sino que, además, Yaxuun B'ahlam IV conecta su propio evento de creación realizado en fechas históricas, con el pasado mítico, al anteponer a su cuenta larga todos los números trece que ya vimos.

$\mathrm{Y}$ es en este evento de creación -y recreación- mítica y sacrificio donde encontramos la segunda y última personificación de Yaxuun B'ahlam IV en la historia de Yaxchilán. Esta personificación tiene lugar tres años después de su primera personificación y es la única vez que se lo menciona asociado a Yax Chiit Jun Witz' Naah Kan. Pero esta personificación es bastante compleja, ya que al parecer está personificando al mismo tiempo a dos seres, o a un ser que reúne los atributos de dos seres distintos. Yax Chiit es un ser sobrenatural poco conocido, que aparece incluso, en una ocasión, como dios en Yaxchilán, en su apelativo de Winik Chiit K'uh (Estela 4, fechada en 775).

Yax Chiit también aparece en algunas ocasiones junto al glifo que se identifica con la Serpiente de Agua. Según Houston y Stuart (1996: 299), en este contexto Yax Chiit aparecía formando personificaciones masculinas, quizás como un referente mitológico. Por otra parte, el glifo identificado con la Serpiente de Agua, Stuart (2007) lo ha descifrado como Jun Witz' Naah Kan «Uno Rocío Primera Serpiente» ${ }^{20}$. Este personaje ha sido llamado también serpiente lirio acuático o nenúfar y «monstruo imix» (Figura 7). Taube la relaciona con el dios $\mathrm{H}$ de Schellhas, pero señala que no hay suficiente evidencia como para considerarla la contraparte Clásica de ese dios. También la asocia con las entidades que personifican las variantes de cabeza de los números trece y tres, $\mathrm{y}$ con atributos del viento, ya que a veces aparece asociada al signo $i k$ '. Por esta razón, sugiere que podría funcionar como un dios del viento, y como una posible contraparte del Clásico maya de la deidad del Centro de México Quetzalcoatl (Taube 1992: 56-63). Sin embargo, de momento es dudosa su categoría divina, ya que al menos en Yaxchilán, no aparece mencionada como dios, $k^{\prime} u h$.

19 Esta fecha corresponde a millones de años antes de Cristo.

20 Stuart (2007), lee Naah como Noh, traduciéndolo como «gran, grande», no obstante, naah significa «primero/a» y es así como lo traduciré. 
Figura 7: Jun Witz' Naah Kan o «Uno Rocío Primera Serpiente», conocida también como la Serpiente de Agua. Dibujo de Linda Schele.

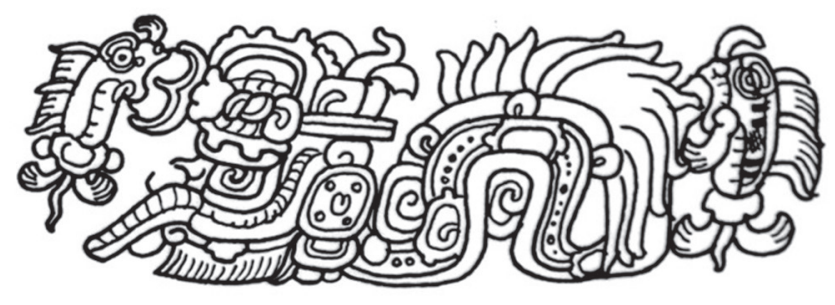

Figura 8: Escalera Jeroglífica 2, Escalón 7. Detalle del tocado de Yaxuun B'ahlam IV que indica la personificación de Jun Witz' Naah Kan.

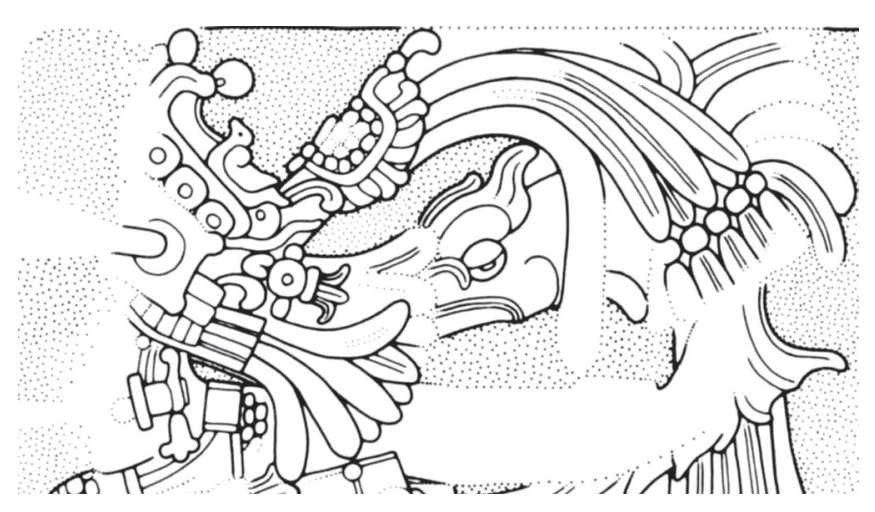

La Serpiente de Agua aparece muchas veces en cerámica, usualmente dentro del simbolismo del llamado «mundo acuático». En escultura aparece frecuentemente en la vestimenta ritual de gobernantes y nobles, en conexión con ritos de fin de período (Stuart 2007). Como vemos, uno de sus atributos es llevar un lirio acuático junto a un pez que come esa flor, y esa misma representación aparece en el tocado de Yaxuun B'ahlam IV (Figura 8), indicando así, la personificación de Jun Witz' Naah Kan, un ser asociado al inframundo debido a sus atributos acuáticos. Es posible que el otro personaje que tiene Yaxuun B'ahlam IV en su tocado represente a Yax Chiit, pero esto deberá contrastarse a futuro con un estudio iconográfico completo de ese ser.

En síntesis, el análisis del Escalón 7 de la Escalera Jeroglífica 2, indica que el ser que está personificando Yaxuun B'ahlam IV, Yax Chiit Jun Witz' Naah Kan -que podría traducirse como «Primero [...] Uno Rocío Primera Serpiente»-, está asociado al inframundo, al mundo acuático, al sacrificio humano, al juego de pelota y probablemente a la guerra, considerando su uso como apelativo de Yaxuun B'ahlam III -el abuelo de Yaxuun B'ahlam IV-, en un contexto bélico (Escalera Jeroglífica 3, Escalón 5). También es posible que se asocie con rituales de eventos míticos.

Queda pendiente dilucidar si Yaxuun B'ahlam IV está personificando a dos seres sobrenaturales distintos, o a un solo ser sobrenatural que está encarnando los atributos de dos seres sobrenaturales, uno de los cuales - Yax Chiit- incluso podría ser un dios, debido al paralelo que existe con Winik Chiit K'uh.

Siguiendo con la temática del juego de pelota, encontramos la única personificación relacionada con un dios masculino en Yaxchilán: el dios del Viento. El texto que 


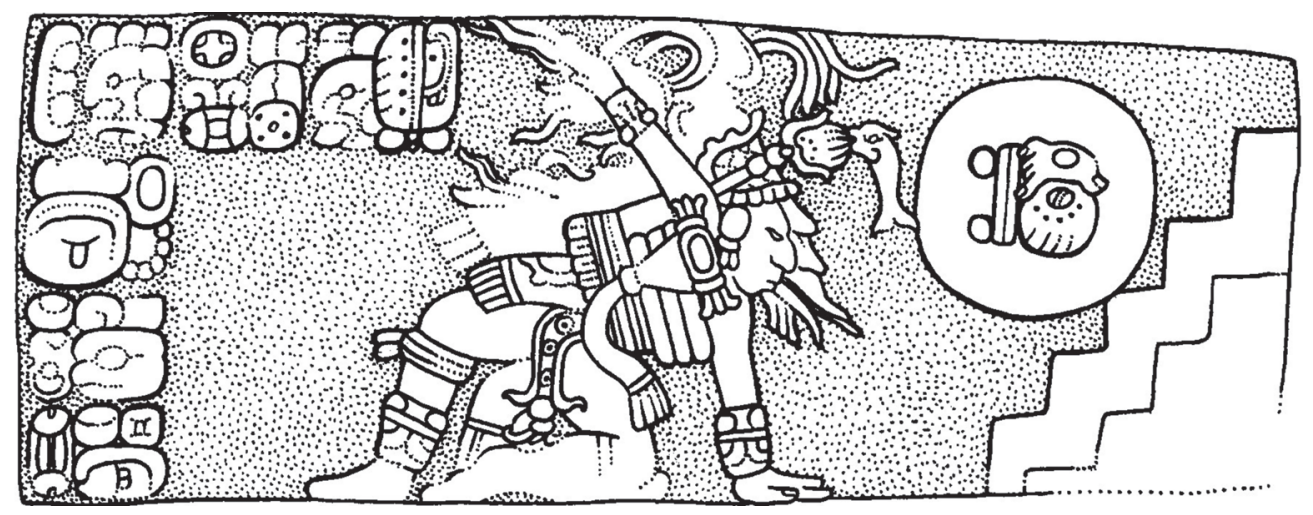

Figura 9: Escalera Jeroglífica 2, Escalón 10. El primer sajal de Yaxuun B'ahlam IV, K’an Tok Wayaab', personificando al dios del Viento. Dibujo de Ian Graham.

nos indica ese evento aparece, sin fecha, en el Escalón 10 de la Escalera Jeroglífica 2. Pero como éste se asocia con el que ya vimos (Escalón 7), podemos asumir que nos señala un evento anterior al ascenso al poder de Yaxuun B'ahlam IV, o por lo menos, contemporáneo al gobierno de éste.

Lo curioso es que no aparece el gobernante personificando al dios del Viento, sino su $B$ 'aah Sajal, su «Primer noble/principal», quien también está jugando a la pelota y vestido de manera ad hoc. El texto dice: ub 'aahil a'n Ik'k'uh [...] K'an Tok Wayaab' b'aah sajal, "el primer sajal K'an Tok Wayaab', es la personificación del dios del Viento» (Figura 9). La iconografía complementa el texto, ya que K'an Tok Wayaab' usa una máscara de «rayos X» con los atributos - boca en forma de pico-del dios del viento mesoamericano. En su tocado lleva el símbolo de la Serpiente de Agua -Jun Witz' Naah Kan-, lo que ratifica la relación de ésta con el viento.

En la Estela 11, fechada el 3 de mayo de 752 d.C., día en que Yaxuun B'ahlam IV ascendió al poder, aparece nuevamente su madre personificando a un ser sobrenatural. El texto señala: ub'aahil a'n «vasija invertida»l ixik k'uh ixik Uh Chan na' ajk'uhu'n, «la sacerdotisa, señora Uh Chan, es la personificación de la diosa 'vasija invertida'» (Figura 10). Este es uno de los monumentos en que Yaxuun B'ahlam IV se encargó de consignar su joyaj ti ajawlel «debut en el señorío» o entronización. Este importantísimo evento lo recalcó antecediendo la cuenta de 819 días, y representando a sus padres ya muertos, como testigos de esa ceremonia ${ }^{21}$. De hecho, su madre falleció un año antes de su entronización, y su hijo la representa personificando a la diosa «vasija invertida» en calidad de testigo de su ascensión al poder. Es probable que a su padre también lo hubiese representado personificando a un dios u otro ser sobrenatural, como lo sugiere su tocado, pero no se ha conservado la parte de la inscripción que debería referirse a dicha personificación.

21 Los padres muertos se representan en el lado contrario de la estela donde se señalan las ceremonias descritas en el texto (entronización y baile). La muerte de «Dios D» B'ahlam II aparece en el Dintel 27, y está fechada en 9.15.10.17.14 6 Hix 12 Yaxk'in (15 de junio de 742), y la muerte de la señora Uh Chan aparece en el Dintel 28, y está fechada en 9.15.19.15.3 10 [Ak'b’al] 16 Wo (13 de marzo de 751) (Kettunen et al. 2002). 


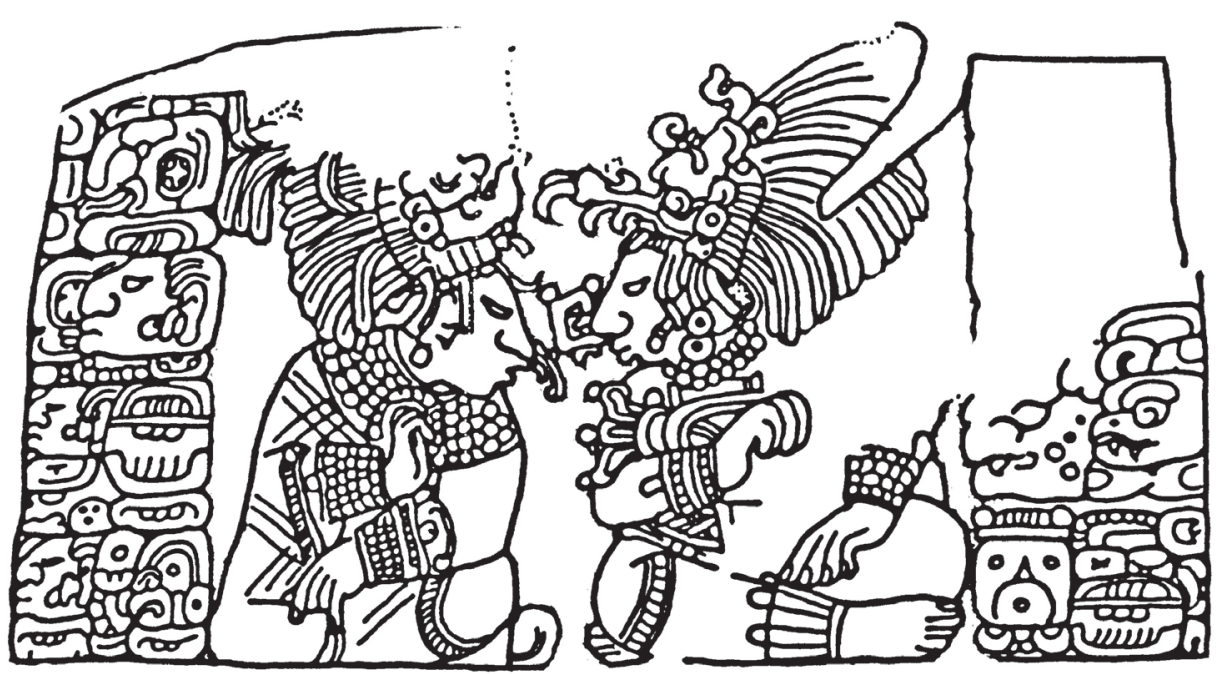

Figura 10: Detalle de la Estela 11 (dorso) donde aparecen los padres muertos de Yaxuun B'ahlam IV. La señora Uh Chan personifica a la diosa «vasija invertida». Dibujo de Linda Schele.

El nombre de la diosa «vasija invertida» aún no se ha descifrado, pero aparece bastante en la zona del Usumacinta, antecediendo nombres de mujeres, por eso se identifica con un «título femenino» (Grube 2012). Este signo está asociado a las mujeres más importantes de Yaxchilán, las que generalmente lo llevaban como apelativo, sin señalar una personificación. De hecho, la Estela 11 y el Dintel 15 son los únicos casos donde se explicita la personificación de esa diosa, por la madre y una de las esposas de Yaxuun B'ahlam IV. Grube asocia el glifo «vasija invertida» con el signo $k$ 'in infijo, con la vieja diosa del agua que aparece en los códices, llamada Chak Chel, probablemente «gran arcoíris» según el autor, a la que muchas veces se la representa derramando una jarra con agua (Grube 2012: 138).

Lamentablemente, el tocado que lleva la Señora Uh Chan no se ha conservado completo, perdiéndose buena parte de lo que podría ser la representación de la diosa que personifica. Sólo quedan los vestigios de un ser cuya naturaleza no se identifica.

Finalmente, el último monumento que consigna una personificación durante el gobierno de Yaxuun B'ahlam IV es el Dintel 15, fechado en el año 755 o 768. En éste la protagonista es la Señora Wak Tuun, una de las cuatro esposas de Yaxuun B'ahlam, y el texto señala: tzahkaj Yax "Chiit» Naah Kan uwahy K'awiil i tzak Yax Tz'aw [Je...n] «kab'» GE.YAX.22 / ub'aahil a'n «vasija invertida» ixik k'uh ixik wak tuun ixik ik'a' ajaw ixik b'aah kab', "fue conjurado Yax 'Chiit' ${ }^{23}$ Naah Kan, el wahy de K'awiil, y entonces (se lo) conjuró (en) Yax Tz'aw [...] (de la) tierra de (Yaxchilán).

22 GE.YAX.2 es la abreviación de Glifo Emblema de Yaxchilán 2, un logograma que no ha sido descifrado, pero que forma parte de lo que se conoce como el reino de Yaxchilán, sugiriendo que dicho reino estaba conformado por dos lugares distintos (Pa'chan y GE.YAX.2).

23 Christian Prager (2013: 369, tabelle 53) lee el logograma como CHIT, pero esta lectura no es segura. En cambio Valencia y García (2010: 245) lo leen como TE'. 




Figura 11: Dintel 15. La Señora Wak Tuun realiza un ritual de conjuro y personifica a la diosa «vasija invertida». Dibujo de Ian Graham (1977).

La Señora de los seis tunes, reina de Ik'a' (Motul de San José), cabeza/primera de la tierra (princesa), es la personificación de la diosa 'vasija invertida'» (Figura 11).

El texto indica que la Señora Wak Tuun realiza un conjuro al wahy de K'awiil, en un lugar nombrado como Yax Tz'aw [...] de la tierra de Yaxchilán, mientras ella personifica a la diosa «vasija invertida». La iconografía no la representa aparentemente con algún atributo que pudiera asociarse a la diosa en cuestión. En este caso, el wahy de K'awiil aparece nombrado como «Primero 'Chiit' Primera Serpiente», lo que podría relacionarlo a Yax Chiit, en caso de que la lectura del logograma en variante de cabeza fuera correcta.

Es interesante observar que esta mujer, procedente de Motul de San José, no sólo está personificando a la única diosa que se registra en Yaxchilán, sino que también está realizando un importante ritual, conjurando en este caso, al wahy de K'awiil en Yax Tz'aw [...] de la tierra de Yaxchilán. Es probable que con estos importantes rituales (de personificación y conjuro al wahy de K'awiil), Yaxuun B'ahlam IV se haya encargado de naturalizar a esta mujer extranjera en su ciudad, con esta especie de prueba iniciática.

\section{Contextos de personificaciones en el reinado de Chelew Chan K'inich}

En el gobierno del hijo de Yaxuun B'ahlam IV encontramos el último monumento de Yaxchilán en donde aparece la frase $u b^{\prime}$ 'aahil a'n. El Dintel 14, fechado el 1 de julio 
Figura 12: Dintel 14. La madre y el tío materno de Chelew Chan K'inich realizando rituales. La señora Chak Joloom personifica a la reina de GE.YAX.2 (Yaxchilán),

la señora Yax Jal, y conjura al wahy K'awiil de la diosa «vasija invertida» que ella representa.

El sajal Chak Joloom realiza un ritual de penitencia y personifica a Yax Chiit. Dibujo de Ian Graham (1977).

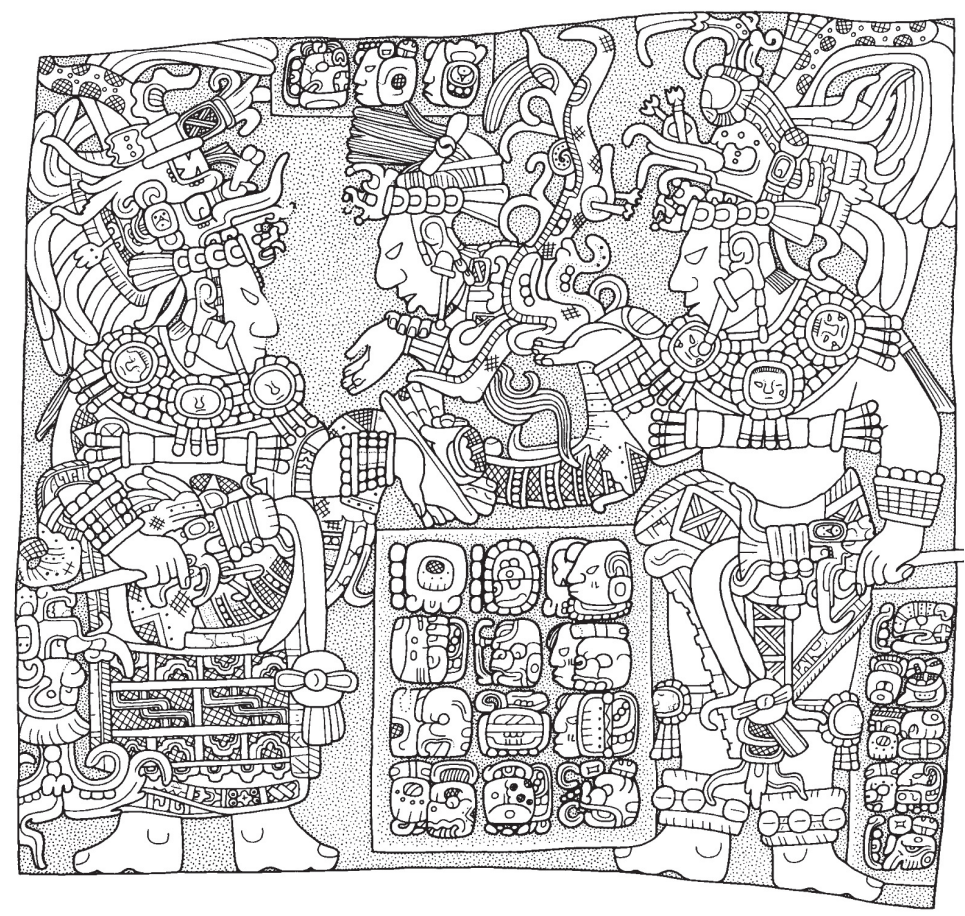

de 741, nos narra de manera retrospectiva un ritual llevado a cabo por la madre y el tío materno ${ }^{24}$ de Chelew Chan K'inich, ambos procedentes del sitio Uchan (Alfonso Lacadena, com. pers., abril 2014). El texto señala: ub'aahil a'n Ixik GE.YAX.2 ajaw ixik Yax Jal, «(La Señora Chak Joloom) ${ }^{25}$ es la personificación de la reina de (Yaxchilán), la señora Yax Jal» (Figura 12). Luego, el texto relata: tzahkaj K'awiil «Kab' Muwaan» Chanal Chak B'ay Kan uwahylajiiy/uwahyjalay? "vasija invertida» ixik k'uh ixik Chak Joloom Ixik sajal [ya..n] ajaw, «fue conjurado K'awiil Kab' Muwaan Chanal Chak B'ay Kan el 'wahy' 26 de la diosa 'vasija invertida' señora Chak Joloom señora sajal, madre del rey». Y finalmente, el texto indica: ub 'aahil a'n Yax Chiit [...]

24 Aparentemente Chak Joloom fue el hermano de la señora Chak Joloom, y por tanto, cuñado de Yaxuun B'ahlam IV (Helmke 2010: 7, 8).

25 El texto se encuentra a modo de viñeta junto a la representación de la Señora Chak Joloom, quien es mencionada en el pasaje que sigue a continuación.

26 La expresión consignada se lee wahylajiiy o wahyjalay, y correspondería a una forma sustantiva derivada de la raíz wahy (Alfonso Lacadena, com. pers. marzo 2015). Como de momento no tiene una traducción segura, la traduciré como wahy, atendiendo al contexto epigráfico e iconográfico. Prager lo transcribe wayjalay (tabelle 53: 369), Valencia y García (2010: 246) lo transcriben como uwayal jay y lo traducen como «el way de». Guido Krempel (com. pers. febrero 2015) transcribe la frase uwahy jay «el tazón/vasija del wahy (de la señora Chak Joloom)», sugiriendo que la expresión alude al plato que aparece en la iconografía, por donde estaría saliendo el wahy. Sin embargo, el wahy no está saliendo del plato, sino que está rodeando a los dos personajes; además, jay significa «tazón», no plato, como el que se ve en la iconografía, así es que la palabra correcta, atendiendo a la iconografía, debería ser lak «plato», no jay. Por otro lado, la palabra jay se hace con los fonemas ja-yi en las inscripciones del Clásico; con los fonemas ja-ya (como se ve en la inscripción) se escribe en un periodo más tardío (Alfonso Lacadena, com. pers. marzo 2015). 
ch'ahb'ak'ab' [...] Chak Joloom sajal Uchan ajaw, «el sajal Chak Joloom, señor de Uchan, en su génesis y oscuridad [...] es la personificación de Yax Chiit».

Como podemos ver, nuevamente estamos frente a un ritual de conjuro al wahy K'awiil y de personificaciones. El wahy K'awiil -cuyo nombre se podría traducir como «Tierra Gavilán Celestial Gran Serpiente Guia»- es señalado como el wahy de la diosa «vasija invertida», la Señora Chak Joloom, dando a entender que esta señora probablemente al estar personificando a la Señora Yax Jal de GE.YAX.2, está personificando a la diosa «vasija invertida» de Yaxchilán, la única diosa (en términos de género) reconocida en Yaxchilán, y probablemente patrona del sitio. La Señora Yax Jal debió ser un ancestro de Yaxchilán probablemente asociada a la diosa «vasija invertida» de dicho sitio.

La Señora Chak Joloom lleva en su tocado la cabeza de un ser similar a K'awiil, que tiene en su frente un signo $k^{\prime}$ in, al igual que el glifo «vasija invertida». Este ser podría estar más asociado a la diosa «vasija invertida», que a la Señora Yax Jal, debido al signo $k^{\prime}$ 'in que lleva infijo.

El ser que sale de las fauces del wahy podría ser un hombre o una mujer. Sin embargo, comparte un atributo con los hermanos Chak Joloom, la diadema con cabeza de «bufón», la cual podría estar indicando alguna filiación con Yaxchilán o, al menos, un vínculo real con ese sitio.

Finalmente, el señor Chak Joloom está personificando a Yax Chiit a través del ritual de penitencia o autosacrificio que llevó a cabo, idea que se refuerza con el punzador que lleva en su mano. Es probable que la cabeza de chapaht «ciempiés» -o quizás la fusión de ciempiés y serpiente (Kettunen 2006: 97; Kettunen y Davis 2004: 3)-, que lleva en su tocado, esté relacionada con la personificación de Yax Chiit.

\section{Conclusiones}

De lo analizado hasta ahora respecto a los seres sobrenaturales mencionados en los textos de Yaxchilán, se puede concluir que el ser que personifica Yaxuun B'ahlam IV, «Te'el» Kuy Xukub' «vasija invertida» Chan [...] Mixnal, es una importante entidad asociada, probablemente, al linaje de Yaxchilán ${ }^{27}$; sin embargo, no se consideraba un dios, ya que nunca se lo mencionó como tal. Posiblemente fue un ancestro patrono de la ciudad. El análisis de su nombre nos indica que este ser se asocia al inframundo, a la lechuza, ave nocturna también relacionada con ese lugar, y también a Yax Chiit, personaje poco conocido hasta ahora. En algunos monumentos, parte de su nombre se vincula con la cuenta de 819 días.

En Yaxchilán también existió la única deidad femenina, y al parecer patrona del sitio, que se asoció a las mujeres de la realeza, las que llevaban su nombre como apelativo. Sin embargo, sólo en dos textos se señala la explícita personificación de esta diosa, por dos mujeres distintas asociadas a Yaxuun B'ahlam IV.

Es probable que el culto a la diosa «vasija invertida» se originara a partir de algún ancestro mítico femenino, deificado con el tiempo, de Yaxchilán o de la zona del Usu-

27 Este ser sobrenatural aparece formando parte de los apelativos de Yaxuun B'ahlam II y III, los gobernantes $8^{\circ}$ y $12^{\circ}$ de Yaxchilán, respectivamente. 
macinta, ya que es en esa área donde se encuentra más representada esa diosa ${ }^{28}$. La diosa «vasija invertida» con frecuencia aparece asociada a rituales de conjuro donde se invocaron diversos seres, posiblemente ancestros de Yaxchilán.

Los rituales de conjuro al wahy de K'awiil están asociados a los rituales de personificación. De hecho, O’Neil (2011: 265) señala que la forma para contactarse con los ancestros y traerlos al tiempo presente, se realizaba a través de conjuros y personificaciones. Al parecer la función principal de los rituales de conjuro al wahy de $\mathrm{K}$ 'awiil fue para invocar a los ancestros. Es posible que para conjurar a un dios no se haya necesitado de la mediación de K'awiil; en cambio, la conjuración a los ancestros quizás necesitaba la conexión con el mundo de los muertos a través de K'awiil, siendo éste el mediador sobrenatural que unía momentáneamente el mundo de los vivos con el de los muertos. Esto explicaría en gran medida por qué el nagualismo se asociaba con especialistas rituales, o brujos -actualmente-, ya que ellos son las personas capaces de poder conectar el mundo de los vivos con el de los muertos y seres sobrenaturales, al igual que K'awiil, el representante del fenómeno wahy ${ }^{29}$ del Clásico, por excelencia. De esta forma, los rituales de conjuro a K'awiil pudieron ser, en gran medida, rituales necrománticos, o sea, de «adivinación o revelación por las almas de los muertos» (Vázquez y Muñoz 1997: 304).

Una pregunta importante por considerar en el futuro es si los conjuros a K'awiil son los que permiten las personificaciones, o si es necesario estar personificando a un ser sobrenatural para poder conjurar a K'awiil.

AgradeCIMIENTos: Quiero agradecer a los doctores Alfonso Lacadena García-Gallo y Harri Kettunen el tiempo que han dedicado a revisar y comentar, de manera muy asertiva, anteriores versiones de este artículo. Asimismo, agradezco a Esteban Aguayo sus comentarios y correcciones formales. No obstante, los errores puntuales o de interpretación que pueda haber son de mi absoluta responsabilidad.

\section{Referencias bibliográficas}

Academia de Lenguas Mayas de Guatemala (ALMG)

2003 Muuch't'an Mopan / Vocabulario Mopan. Ciudad de Guatemala.

ArzÁPALO Marín, Ramón

1995 Calepino de Motul. Diccionario Maya-Español. México: Instituto de Investigaciones Antropológicas, UNAM.

Asensio Ramos, Pilar

2015 El way en la cerámica polícroma del Clásico Tardío maya. Tesis Doctoral. Facultad de Geografía e Historia. Universidad Complutense de Madrid.

BARRERA VÁSQUEZ, Alfredo

1980 Diccionario Maya Cordemex. Mérida: Cordemex.

\footnotetext{
28 No obstante, no se puede descartar que el uso del apelativo que señala a la diosa, corresponda a algún título femenino que usaron algunas mujeres del Usumacinta (Grube 2012).

29 El fenómeno wahy es la contraparte, en el Clásico maya, del fenómeno del nagualismo colonial y contemporáneo.
} 
Bоот, Erik (comp.)

1997 Vocabulario Lacandón Maya-Español (Dialecto de Naja'). Documento electrónico, http://www.famsi.org/mayawriting/dictionary/boot/lacandon-de-naja_basedon_bruce1968.pdf, con acceso el 3/9/2014.

Códice Laud

1966 Codex Laud, edición facsimilar. Graz: Akademische Druck und Verlagsanstalt.

FAsH, William, Alexandre ToKovinine y Barbara FASH

2009 «The House of New Fire at Teotihuacan and Its Legacy in Mesoamerica», en Art of Urbanism: How Mesoamerican Kingdoms Represented Themselves in Architecture and Imaginery, William Fash y Leonardo López Luján, eds., pp. 201-229. Washington, D.C.: Dumbarton Oaks Research Library and Collection.

FreIDEL, David, Linda Schele y Joy PARKer

1993 Maya Cosmos: Three Thousand Years on the Shaman's Path. Nueva York: Quill.

GRAHAM, Ian

1977 Corpus of Maya Hieroglyphic Inscriptions, Vol. 3, part I, Yaxchilan, con Eric von Euw. Cambridge: Peabody Museum of Archaeology and Ethnology, Harvard University.

1979 Corpus of Maya Hieroglyphic Inscriptions, Vol. 3, part II, Yaxchilan. Cambridge: Peabody Museum of Archaeology and Ethnology, Harvard University.

1982 Corpus of Maya Hieroglyphic Inscriptions, Vol. 3, part III, Yaxchilan. Cambridge: Peabody Museum of Archaeology and Ethnology, Harvard University.

GRUBE, Nikolai

2012 «A Logogram for SIP, 'Lord of the Deer'». Mexicon 34 (6): 138-141.

Helmke, Christophe

2010 «The Transferral and Inheritance of Ritual Privileges: A Classic Maya Case from Yaxchilan, Mexico». Wayeb Notes 35: 1-14.

Houston, Stephen D. y Andrew Scherer

2010 «La ofrenda máxima: el sacrificio humano en la parte central del área maya», en El sacrificio humano en la tradición religiosa mesoamericana, Leonardo López Luján y Guilhem Olivier, coords., pp. 169-193. México: INAH / UNAM - IIH.

Houston, Stephen D. y David StuarT

1996 «Of Gods, Glyphs and Kings: Divinity and Rulership among the Classic Maya». Antiquity 70: 289-312.

1998 «The Ancient Maya Self: Personhood and Portraiture in the Classic Period». RES: Anthropology and Aesthetics 33: 73-101.

Kettunen, Harri

2006 Nasal Motifs in Maya Iconography, 2a ed. Helsinki: University of Helsinki.

Kettunen, Harri y Bon V. Davis

2004 «Snakes, Centipedes, Snakepedes, and Centiserpents: Conflation of Liminal Species in Maya Iconography and Ethnozoology». Wayeb Notes 9: 1-42.

Kettunen, Harri, Christophe Helmke y Stanley P. Guenter

2002 Transcriptions and Transliterations of Selected Texts from Yaxchilan, Chiapas, Mexico. Londres: Communications in Print plc \& University College London. 
KnOwLton, Timothy

2010 Maya Creation Myths: Words and Worlds of the Chilam Balam. Boulder: University Press of Colorado.

LACADENA, Alfonso

2010 Introducción a la escritura jeroglifica maya. Cuaderno de Trabajo 1. 15 Conferencia Maya Europea, Madrid, 30 de noviembre-2 de diciembre.

LACADENa, Alfonso y Søren WichmanN

2004 «On the Representation of the Glottal Stop in Maya Writing», en The Linguistics of Maya Writing, Søren Wichmann, ed., pp. 103-162. Salt Lake City: The University of Utah Press.

2005 «Harmony Rules and the Suffix Domain: A Study of Maya Scribal Conventions». Documento electrónico, http://email.eva.mpg.de/ wichmann/harm-rul-suf-dom7. pdf, con acceso el 3/9/2014.

LANDA, Fray Diego de

1959 Relación de las cosas de Yucatán. México: Porrúa.

LOPES, Luís y Albert DAVLETSHIN

2004 «The Glyph for Antler in the Mayan Script». Wayeb Notes 11: 1-18.

López Austin, Alfredo

2006 «Mitos e íconos de la ruptura del Eje-Cósmico: Un glifo toponímico de las piedras de Tízoc y del Ex-Arzobispado». Anales del Instituto de Investigaciones Estéticas 89: 93-134.

2008 Cuerpo humano e ideología. Las concepciones de los antiguos nahuas. México: UNAM.

LóPez Oliva, Macarena

2013 El ritual de la decapitación y el culto a las cabezas trofeo en el mundo maya. Tesis de maestría. Instituto de Investigaciones Filológicas, Facultad de Filosofía y Letras, UNAM.

Martin, Simon

2003 «In Line of the Founder: A View of Dynastic Politics at Tikal», en Tikal: Dynasties, Foreigners, and Affairs of State, Jeremy Sabloff, ed., pp. 3-46. Santa Fe: School of American Research Press.

Martin, Simon y Nikolai GrubE

2002 Crónica de los reyes y reinas mayas. Barcelona: Crítica.

Mathews, Peter

1997 La escultura de Yaxchilán. Ciudad de México: INAH.

Nehammer Knub, Julie, Simone Thun y Christophe Helmke

2009 «The Divine Rite of Kings: An Analysis of Classic Maya Impersonation Statements», en The Maya and their Sacred Narratives: Text and Context in Maya Mythologies, G. Le Fort, R. Gardiol, S. Matteo y C. Helmke, eds, pp. 177-195. Acta Mesoamericana 20. Markt Schwaben: Verlag Anton Saurwein.

Noguez, Xavier

2006 «Códice Laud». Arqueología Mexicana 79: 72-73.

O’NEIL, Megan E.

2011 «Object, Memory, and Materiality at Yaxchilan: The Reset Lintels of Structures 12 and 22». Ancient Mesoamerica 22 (2): 245-269. 
Prager, Christian

2013 Übernatürliche Akteure in der Klassischen Maya-Religion. Tesis doctoral. Rheinischen Friedrich-Wilhelms-Universität, Bonn.

Schele, Linda y David FreIDEL

1990 A Forest of Kings: The Untold Story of the Ancient Maya. Nueva York: William Morrow and Company.

SCHELE, Linda y Nikolai GRUBE

1990 «Six-Staired Ballcourts». Copan Notes 83.

SCHELE, Linda y Peter Mathews

1998 The Code of Kings. Nueva York: Scribner.

STUART, David

1998 «The Fire Enters His House': Architecture and Ritual in Classic Maya Texts», en Function and Meaning in Classic Maya Architecture, Stephen Houston, ed., pp. 373-425. Washington, D.C.: Dumbarton Oaks Research Library and Collection.

2000 "The Arrival of Strangers'. Teotihuacan and Tollan in Classic Maya History», en Mesoamerica's Classic Heritage. From Teotihuacan to the Aztecs, David Carrasco, Lindsay Jones y Scott Sessions, eds., pp. 465-513. Boulder: University Press of Colorado.

2003 «La ideología del sacrificio entre los mayas». Arqueología Mexicana 63: 24-29.

2004 «The Beginnings of the Copan Dynasty: A Review of the Hieroglyphic and Historical Evidence», en Understanding Early Classic Copan, Ellen Bell, Marcello Canuto y Robert Sharer, eds., pp. 215-248. Filadelfia: University of Pennsylvania Museum of Archaeology and Anthropology.

2005 «Glyphs on Pots. Decoding Classic Maya Ceramics», en Sourcebook for the 29th Maya Hieroglyphic Forum, pp. 110-197. Austin: The University of Texas at Austin, Department of Art and History, Maya Workshop Foundation.

2007 «Reading the Water Serpent as WITZ'». Maya Decipherment, Blog personal, https://decipherment.wordpress.com/2007/04/13/reading-the-water-serpent/, con acceso el 3/9/2014.

TAuBE, Karl

1992 The Major Gods of Ancient Yucatan. Studies in Pre-Columbian Art \& Archaeology 32. Washington, D.C.: Dumbarton Oaks Research Library and Collection.

Thомеsом, J. Eric S.

1962 A Catalog of Maya Hieroglyphs. Norman: University of Oklahoma Press.

Tokovinine, Alexandre

2014 «The House of the Rising Sun: Imagery and Text on the Roof Frieze of Building A-sub, Group II, Holmul». Manuscrito en posesión del autor.

UlRich, E. Matthew y Rosemary Dixon de UlRich

1976 Diccionario Maya Mopán/Español, Español/Maya Mopán. Guatemala: Instituto Lingüístico de Verano.

VALENCIA, Rogelio y Ana García Barrios

2010 «Rituales de invocación al dios K'awiil», en El ritual en el mundo maya: de lo privado a lo público, Andrés Ciudad, Ma Josefa Iglesias y Miguel Sorroche, eds., pp. 235-261. Madrid: Sociedad Española de Estudios Mayas. 
VÁzQuez Hoys, Ana María y Oscar MuÑoz MarTín

1997 Diccionario de magia en el Mundo Antiguo. Madrid: Aldebarán.

VELÁSQUEz GARCÍA, Erik

2007 «La máscara de 'rayos X'. Historia de un artilugio iconográfico en el arte maya». Anales del Instituto de Investigaciones Estéticas 90: 7-36.

2009 Los vasos de la entidad política de 'Ik': una aproximación histórico-artística, Tesis Doctoral. Posgrado en Historia del Arte. Facultad de Filosofía y Letras. México: UNAM.

2010 «Naturaleza y papel de las personificaciones en los rituales mayas, según las fuentes epigráficas, etnohistóricas y lexicográficas», en El ritual en el mundo maya: de lo privado a lo público, Andrés Ciudad, M Josefa Iglesias y Miguel Sorroche, eds., pp. 203-233. Madrid: Sociedad Española de Estudios Mayas.

ZENDER, Marc

2004 «Glyphs for 'Handspan' and 'Strike' in Classic Maya Ballgame Texts». The PARI Journal IV (4): 1-9. Documento electrónico, http://www.mesoweb.com/pari/publications/journal/404/Handspan.pdf, con acceso el 3/9/2014. 